\title{
Cimetidine for peptic ulcer in patients with arthritis
}

\author{
J. R. CROKER, P. B. COTTON, A. C. BOYLE, AND P. KINSELlA \\ From the Gastrointestinal Unit, Middlesex Hospital, London WI
}

SUMmARY Patients taking anti-inflammatory drugs for arthritis are prone to dyspepsia, and management of peptic ulcer is difficult because surgery is poorly tolerated. In this open study cimetidine treatment was associated with ulcer healing in 17 out of 21 patients with arthritis even when anti-inflammatory treatment was continued. Remission was maintained for 1 year by continued cimetidine therapy.

It is widely believed that patients with arthritis and similar conditions taking anti-inflammatory drugs have an increased incidence of dyspepsia and peptic ulceration. Evidence for this belief is poor except perhaps in patients with rheumatoid arthritis. However, when dyspeptic problems do occur in such patients, management often proves difficult. Patients are often elderly and frail and need the anti-inflammatory drugs which may be aggravating their condition. Many walk unhappily and unsteadily along a tightrope between the chasms of severe indigestion and severe joint pains.

Cimetidine is well established in the management of peptic ulceration in nonarthritic patients. We thus set out to perform controlled studies of its use in arthritic patients with dyspepsia taking antiinflammatory drugs. However, it soon became evident that cimetidine was effective. For this reason it was not clinically acceptable to allocate half the patients to placebo or alternative alkaline regimen when many had to continue with antiinflammatory drugs and had life-threatening lesions for which the alternative treatment was surgery, for which they were unfit. Thus this report concerns a series of patients treated carefully but openly with cimetidine.

\section{Patients and methods}

Twenty-three patients with arthritis and dyspepsia entered the study after endoscopic confirmation of either oesophagitis or gastric and duodenal ulceration. Six were identified by routine interview of 150 consecutive patients attending at rheumatology clinics; the remainder were referred in the usual way to the Gastrointestinal Unit. Two patients did not

Accepted for publication 9 May 1979.

Correspondence to Dr Croker. complete the initial course of treatment. One was withdrawn after suffering a pathological fracture of the hip, and a second patient refused endoscopy. The remaining 18 females and 3 males have an average age of 63 years (range 37-83 years). Thirteen patients were suffering from rheumatoid arthritis, 12 having moderately active disease and 1 severe active disability. Six patients had osteoarthritis; the remaining 2 had Reiter's disease and psoriatic arthropathy.

Arthritis and dyspepsia began simultaneously in 5 patients, while in 10 patients arthritis antedated dyspepsia. Sixteen patients had previously associated dyspepsia with anti-inflammatory drugs. Eighteen patients previously and 9 at presentation were on multiple anti-inflammatory therapy (Table 1).

Two patients with gastrointestinal bleeding and 1 patient with a perforated duodenal ulcer had previously received surgery. One other patient with a

\section{Table 1 Patients on anti-inflammatory drugs at presentation}

\begin{tabular}{ll}
\hline Single agents & \\
Propionic acid derivatives & 5 \\
$\quad$ Ibuprofen & 2 \\
Ketoprofen & 1 \\
$\quad$ Naproxen & 1 \\
Fenoprofen & 1 \\
Indomethacin & 3 \\
Gold & 1 \\
Penicillamine & 1 \\
Oxphenbutazone & 1 \\
Aspirin Two agents & 1 \\
Prednisone+indomethacin & 1 \\
Prednisone+naproxen & 2 \\
Gold naproxen & 1 \\
Gold +indomethacin & 2 \\
Three agents & \\
Prednisone+azathioprine+ naproxen & 1 \\
Gold+benorylate+sulindac (Clinoril) & 1 \\
Ketoprofen + naproxen+alclofenac (Prinalgin) & 1 \\
\hline
\end{tabular}


gastrointestinal haemorrhage had been treated conservatively.

Seven patients had presented with overt gastrointestinal bleeding. Five had required transfusion of 2 or more units of blood. The remaining 14 patients presented with dyspepsia. The general health of the patients was fair in 8 but only moderate in 9 and poor in 4 . Seven patients had significant complicating medical disease. Six patients smoked more than 10 cigarettes a day.

\section{INITIAL ENDOSCOPIC FINDINGS}

Four patients were suffering from oesophagitis (3 moderate and 1 severe) in association with hiatus hernia (Table 2). Four patients had both duodenal and gastric ulcers. In 13 patients lesions were present in either the stomach (10) or the duodenum (3). The sites of gastric ulceration are shown in Table 2.

\section{MANAGEMENT}

Initial treatment. Cimetidine was taken for 6 weeks at a dose of $1 \mathrm{~g}$ day for duodenal and gastric ulceration and $1.6 \mathrm{~g} /$ day for oesophagitis. Patients were provided with antacid tablets to use when required. Anti-inflammatory treatment was withdrawn or changed where possible. Progress was assessed at 3 and 6 weeks by the use of diary cards, tablet count, a visual analogue scale, and by interview. Blood and urine samples were taken for analysis and any side effects were noted. A second endoscopy was performed after 6 weeks. Patients with unhealed lesions were treated for a further 6 weeks with cimetidine $1.6 \mathrm{~g} /$ day.

Maintenance. Maintenance therapy with cimetidine $400 \mathrm{mg}$ twice daily was continued for 1 year in patients whose peptic lesions had healed. Oesophagitis was judged to have healed when inflammation had improved macroscopically together with symptomatic relief. Patients were reviewed monthly, and arthritis was assessed at 3-monthly intervals. Follow-up endoscopy was done at the end of 1 year or earlier if symptoms relapsed.

Table 2 Results of endoscopy after treatment period (6 weeks). Figures in parentheses refer to patients with rheumatoid arthritis

\begin{tabular}{|c|c|c|}
\hline & Total & Lesions healed \\
\hline Patients & 21 (13) & $15(8)$ \\
\hline Oesophagitis & 4 (3) & $4(3)$ \\
\hline Duodenal ulcer & 7 (4) & 5 (2) \\
\hline Gastric ulcer & 14 (9) & $10(6)$ \\
\hline Lesser curve & 6 (5) & 5 (4) \\
\hline Antrum & 7 (3) & $5(2)$ \\
\hline Stoma & 1 (1) & 0 \\
\hline
\end{tabular}

\section{Results}

INITIAL TREATMENT

Seven patients were improved and 14 asymptomatic at the end of the initial 6 week treatment period. The results of repeat endoscopy are shown in Table 2. Lesions healed in 15 out of 21 patients. All 4 patients with oesopagitis showed improvement both in symptoms and in endoscopic appearances. Complete healing occurred in 5 out of 7 patients with duodenal ulcers and 13 out of 14 with gastric ulcers. Ulcer healing occurred in 8 out of 13 patients with rheumatoid arthritis and in all 6 patients with osteoarthritis. A duodenal ulcer healed in a patient with Reiter's disease, while a gastric ulcer remained unhealed in a patient with psoriatic arthropathy.

The numbers in the study were small, and we could not show whether healing was influenced by anti-inflammatory drugs, smoking habits, age, inpatient treatment, or general health (Table 3). Antiinflammatory treatment was continued in 12 out of 13 patients with rheumatoid arthritis, 1 out of 6 patients with osteoarthritis, and both remaining patients with Reiter's disease and psoriasis. Lesions healed in 10 of these 15 patients after 6 weeks of treatment.

Ulcers were unhealed in 6 patients, 5 of whom continued anti-inflammatory treatment. Repeat endoscopy was performed at 3 months in 5 patients after further therapy, with cimetidine $1.6 \mathrm{~g}$ per day.) Endoscopy showed healed duodenal ulcers in 2 patients but unhealed gastric ulcers in 3 patients. Further endoscopy was not considered appropriate in the remaining aged patient. Symptoms were completely controlled in 3 patients and improved in 3 others.

\section{MAINTENANCE}

Of the 17 patients whose peptic lesions healed 9 have completed 1 year's maintenance and 3 others have completed 6,7 , and 9 months respectively. In

Table 3 Factors influencing healing during treatment period

\begin{tabular}{lll}
\hline & Total & Lesions healed \\
\hline Anti-inflammatory drugs & 11 & 8 \\
$\quad$ Continued & 4 & 2 \\
Reduced & 6 & 5 \\
$\quad$ Withdrawn & 6 & 3 \\
Smoking continued & 11 & 8 \\
Inpatient rest & 8 & 5 \\
General condition & 9 & 7 \\
$\quad$ Fair & 4 & 3 \\
Moderate & & \\
Poor & 63 years & 63 years \\
\hline Mean age &
\end{tabular}


5 other patients the maintenance period has been short (less than 6 months), but all patients remain asymptomatic.

Of the 12 patients who have completed prolonged periods of maintenance initial endoscopy showed oesophagitis in 4 , gastric ulcers in 5 , and duodenal ulcers in 3 . Six patients were suffering from rheumatoid arthritis, 5 from osteoarthritis, and one from Reiter's disease. During the maintenance period anti-inflammatory drug therapy was continued unchanged in 4 patients but increased in 4 others. Four patients with osteoarthritis received no anti-inflammatory drugs during either the treatment or maintenance periods. Symptoms were controlled in 11 out of 12 patients, though 2 patients suffered minor dyspeptic relapses. In both these cases repeat endoscopy showed normal appearances. Final endoscopy at the completion of maintenance treatment gave normal results in those 11 asymptomatic patients. One patient with rheumatoid arthritis and oesophagitis relapsed both clinically and endoscopically when anti-inflammatory treatment was increased. One year later on full dose of cimetidine $1.6 \mathrm{~g}$ /day she remains symptomatically well, and repeat endoscopy showed minimal oesophagitis only.

Of the 4 patients whose ulcers did not heal in the initial treatment period 2 have remained asymptomatic on maintenance cimetidine $400 \mathrm{mg}$ nocte. The 2 remaining patients have continued to have dyspeptic problems, particularly when attempts were made to increase anti-inflammatory treatment.

Side effects. No side effects attributable to cimetidine were noted during either the treatment or maintenance periods.

Laboratory measurements. Abnormal findings were common, but no new abnormalities developed during treatment or maintenance with cimetidine.

Compliance. Patient compliance for cimetidine was high when judged by tablet count and diary records.

\section{Discussion}

The exact frequency of peptic ulceration in rheumatoid patients is difficult to assess. In a review of the literature (Cooke (1967) found a large range but concluded that the frequency was probably increased. In fact we were surprised by the small number of patients referred with dyspeptic problems from a busy rheumatology unit. Figures may vary according to the method of detection, and endoscopic studies have shown a high frequency of ulceration in asymptomatic patients (Sun et al., 1974). In this study only symptomatic patients were investigated. Little information is available docu- menting peptic ulceration in nonrheumatoid arthritis.

The increased frequency of peptic ulceration, if real, may simply reflect the general poor health which is common in these patients. It is known that serious illness is associated with peptic ulceration. In this series the general health of the patients was less than satisfactory in 13 , and 7 patients had significant complicating medical illness.

Any effect of the arthritis is difficult to separate from the action of anti-inflammatory drugs, and assessment of individual drugs is complicated by the multiplicity of them commonly given. All 16 patients who associated dyspepsia with antiinflammatory treatment did so while taking more than 1 drug.

Although most anti-inflammatory drugs have produced gastric lesions in various animal models (Brodie et al., 1962; Davenport 1969; Robert and Nazamis, 1963; Chvasta and Cooke, 1972; Mann and Sachdev, 1976) there is little convincing information in man. Epidemiological studies have indicated an increased frequency of gastric ulcar with heavy use of aspirin (Duggan and Chapman, 1970; Levy, 1974) but not with steroids (Conn and Blitzer, 1976). Endoscopic studies have shown that damage to the gastric mucosa may be caused not only by aspirin (Weiss et al., 1961) but also by indomethacin, phenylbutazone, and propionic acid derivatives (Lanza et al., 1975; Lehtola and Sipponen, 1977). The damage caused by aspirin is acid-dependent (Davenport, 1969). Although acid secretion studies were not performed on any of the patients studied, none were suffering from pernicious anaemia.

The numbers in this trial were small and it would require vast numbers to separate the possible effect of various factors on ulcer healing (Tables 2 and 3). For these reasons it is impossible to form any definite conclusion of the prime contribution of cimetidine therapy. Overall, however, the results are good. During the treatment study healing occurred in 15 out of 21 patients at 6 weeks and 17 out of 21 at 3 months. Eleven of these 17 patients continued to take anti-inflammatory drugs. Patients with rheumatoid arthritis did less well than those with osteoarthritis, healing occurring in 9 out of 13 by 3 months in the former and 6 out of 6 in the latter. Patients with rheumatoid arthritis, however, were less well generally and anti-inflammatory drugs were continued in 12 out of 13 compared to 1 out of 6 with osteoarthritis. It is reassuring that healing occurred in 12 out of 15 patients who continued to take anti-inflammatory drugs during the initial treatment period.

During maintenance therapy all 12 patients had good results, though in 1 case only after an increase 
in cimetidine dosage. Eight out of 12 patients continued to take anti-inflammatory treatment and in 4 cases this was increased to pretreatment levels.

Most patients in this series were elderly and frail and would have tolerated surgery poorly. Cimetidine therapy is safe and provides effective treatment even when it is necessary to continue anti-inflammatory drugs. Overall, only 2 out of 21 patients have not had good long-term results, particularly when worsening arthritis required an increase in antiinflammatory treatment

There are at present no data on which to judge the role of prophylactic cimetidine in patients being started on anti-inflammatory drugs. This may be considered in patients with a past history of significant dyspepsia or ulcer disease, but further studies are required.

We thank Smith, Kline and French Laboratories for their generous support during this study, and our colleagues in the Gastrointestinal and Rheumatology Departments at the Middlesex Hospital for their co-operation.

\section{References}

Brodie, D. A., Marshall, R. W., and Moreno, O. M. (1962). Effect of ulcerogenic drugs on gastric acidity in the rat with chronic fistula. Gastroenterology, 43, 675-679.

Chvasta, T. E., and Cooke, A. R. (1972). The effect of several ulcerogenic drugs on the canine gastric mucosal barrier. Journal of Laboratory and Clinical Medicine, 79, 302-315.
Conn, H. O., and Blitzer, B. L. (1976). Non-association of adrenocorticosteroid therapy and peptic ulcer. New England Journal of Medicine, 294, 473-479.

Cooke, A. R. (1967). Corticosteroids and peptic ulcer. In there a relationship? American Journal of Digestive Diseases, 12, 323-329.

Davenport, H. W. (1969). Gastric mucosal haemorrhage in dogs. Gastroenterology, 56, 439-449.

Duggan, J. M., and Chapman, B. L. (1970). The incidence of aspirin ingestion in patients with peptic ulcer. Medical Journal of Australia, 1, 797-800.

Lanza, F., Rover, G., and Nelson, R. (1975). An endoscopic evaluation of the effects of non-steroidal anti-inflammatory drugs on the gastric mucosa. Gastrointestinal Endoscopy, 21, 103-105.

Lehtola, J., and Sipponen, P. (1977). A gastroscopic and histological double blind study of the effects of Diclofenac sodium and Naproxen on the human gastric mucosa. Scandinavian Journal of Rheumatology, 6, 97-102.

Levy, M. (1974). Aspirin use in patients with major upper gastrointestinal bleeding and peptic ulcer disease. New England Journal of Medicine, 290, 1158-1162.

Mann, N. S., and Sachdev, A. J. (1976). Effect of aspirin, ketoprofen, ibuprofen and naproxen on gastric mucosa. Gastroenterology, 70, A55/913.

Robert, A., and Nezamis, J. E. (1963). Effect of prednisone on gastric mucus content and ulcer formation. Proceedings of the Society of Experimental Biology and Medicine, 114, 545-550.

Sun, D. E., Roth, S. H., Mitchell, C. S., and Englan, D. W. (1974). Upper gastrointestinal disease in rheumatoid arthritis. American Journal of Digestive Diseases, 19, 405-410.

Weiss, A., Pitman, E. R., and Graham, E. C. (1961). Aspirin and gastric bleeding. American Journal of Medicine, 31, 266-278. 